\title{
Effect of ovarian hormones and oral contraceptives on tryptophan metabolism
}

\author{
D. P. ROSE
}

From the Alexander Simpson Laboratory for Metabolic Research, St. Mary's Hospital Medical School, London

SUMMARY Women using oral contraceptives of the combined oestrogen-progestogen type excrete elevated levels of a number of metabolites of the tryptophan-nicotinic acid ribonucleotide metabolic pathway in urine collected after an oral dose of the amino acid. Increased excretions of $N_{1}$-methylnicotinamide reflect an enhanced capacity for the conversion of Ltryptophan to nicotinic acid derivatives, although an additional factor responsible for the abnormal excretion of tryptophan metabolites may be interference with the coenzymic function of vitamin $\mathbf{B}_{6}$.

Similar changes in tryptophan metabolism are observed in human subjects treated with oestrogens alone.

The possible mechanisms for this disturbance of amino acid metabolism, and its clinical significance are discussed.

Recent investigations have shown that the use of oral contraceptives, and the administration of oestrogens alone, is accompanied by a change in metabolism of the amino acid tryptophan (Rose, 1966a; Rose, 1966b; Price, Thornton, and Mueller, 1967; Rose, Brown, and Price, 1968). These studies have been restricted to the metabolic pathway by which L-tryptophan is metabolized to nicotinic acid ribonucleotide.

\section{The Tryptophan-Nicotinic Acid Ribonucleotide Pathway}

The more important intermediate compounds involved in the sequence of reactions leading to the biosynthesis of nicotinic acid ribonucleotide from tryptophan are indicated in Figure 1. The first step is an irreversible oxidation reaction, as a result of which the indole ring of tryptophan is ruptured, and formylkynurenine (not shown) is formed. The enzyme responsible for this reaction is tryptophan oxygenase (tryptophan pyrrolase). Because there is always a vast excess of formamidase present in the liver, formylkynurenine does not accumulate, but is promptly converted oxygenase is assayed in liver preparations other than highly purified enzyme systems, kynurenine, and not its formyl derivative, is determined as the reaction product.

The enzymatic activity of tryptophan oxygenase in a number of species, including the rat and man, is raised by the administration of adrenal glucocorticoids (Knox, 1951; Thomson and Mikuta, 1954; Altman and Greengard, 1966). This raised activity is due to an actual increase in the amount of enzyme protein present, which in turn is consequent upon increased synthesis of messenger RNA (Greengard, Smith, and Acs, 1963). Thus, the steroids concerned are causing a true induction of the enzyme in the sense that the term is used by enzymologists working with mammalian enzyme systems (Greengard, 1967).

Some of the reactions of the tryptophannicotinic acid ribonucleotide pathway require pyridoxal-5-phosphate as a coenzyme (Fig. 1). Vitamin $\mathbf{B}_{6}$ deficiency causes the metabolites kynurenine, 3-hydroxykynurenine, xanthurenic acid, and to a lesser extent kynurenic acid, to be excreted in abnormally large amounts after an oral dose of L-tryptophan (Yess, Price, Brown, Swan, and Linkswiler, 1964). The enzyme which is most sensitive to pyridoxal phosphate depletion appears to be the kynureninase responsible for 


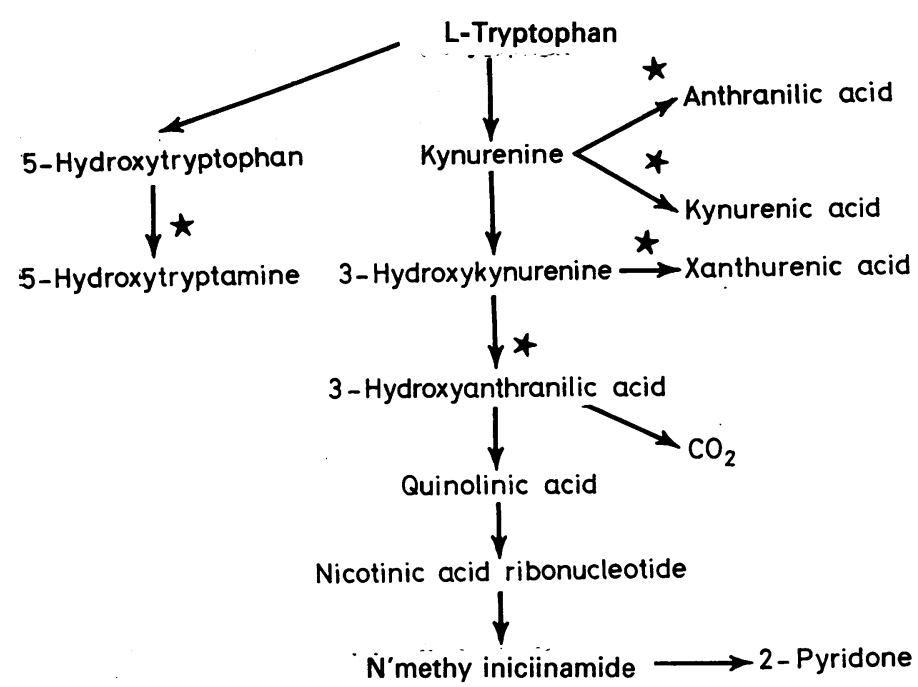

Fig. 1 The metabolic pathway for the biosynthesis of nicotinic acid, ribonucleotide, and 5-hydroxytryptamine from L-tryptophan.

*Known pyridoxal 5-phosphate dependent reactions.

conversion of 3-hydroxykynurenine to 3-hydroxyanthranilic acid. Ogasawara, Hagino, and Kotake (1962) have shown that whereas the activities of kynureninase and the supernatant aminotransferase responsible for the formation of kynurenic acid are markedly decreased in vitamin $\mathrm{B}_{6}$-deficient rats, the level of the mitochondrial aminotransferase, which yields xanthurenic acid, is little affected. These observations probably explain the high excretions of xanthurenic acid, 3-hydroxykynurenine, and kynurenine in vitamin $\mathbf{B}_{\mathbf{6}}$ deficiency.

Nicotinic acid ribonucleotide, the end-product of the biosynthetic sequence from tryptophan, has two major urinary excretion metabolites: $N^{1}$-methylnicotinamide and $N$-methyl-2pyridone-5-carboxamide ('2-pyridone'). Although dietary nicotinic acid will contribute to the concentration of these compounds, the extent of the rise in their excretion after an oral dose of L-tryptophan can be regarded as an index of the capacity for the conversion of the amino acid to nicotinic acid ribonucleotide.

\section{Oral Contraceptives, Oestrogens, and Tryptophan Metabolism}

Women who are taking oestrogen-progestogen preparations, usually for contraceptive purposes, excrete grossly raised levels of metabolites of the tryptophan-nicotinic acid ribonucleotide path-

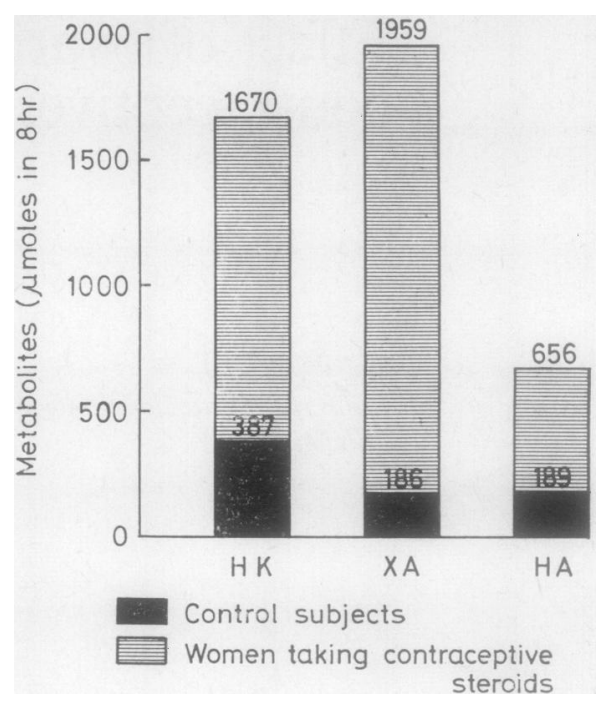

Fig. 2 The excretion of 3-hydroxykynurenine (HK), xanthurenic acid $(X A)$, and 3-hydroxyanthranilic acid $(H A)$ in urine collected for eight hours after a $5 \vec{F}$ oral dose of L-tryptophan. The figures above the columns are the mean values for each group.

way in urine collected after an oral dose of L-tryptophan. Originally, quantitative data were़े restricted to xanthurenic acid excretions (Rose $\frac{0}{\mathrm{O}}$ 1966a), although examination of paper chro응 matograms indicated that high levels of othep metabolites, notably kynurenine, 3-hydroxy kynurenine, 3-hydroxyanthranilic acid, and the 8-methylether of xanthurenic acid, were also. present. Further investigation showed that the concentrations of 3-hydroxykynurenine and 3hydroxyanthranilic acid were definitely raised in. urine collected after the administration of 5 L-tryptophan to women using oral contraceptives but that the excretion of all metabolites becames normal if large doses of pyridoxine were given? before the tryptophan load (Rose, 1966b) Figure 2 compares the mean excretions of $3 \overline{\bar{F}}$ hydroxykynurenine, xanthurenic acid, and 3-hydroxyanthranilic acid by 15 women taking an oestrogen-progestogen preparation with the्్ excretions by 10 women of similar age who were not taking any hormone preparations.

The effect of oral contraceptives on tryptophain metabolism has been confirmed by Dr Jamesp Price and his colleagues at the University of Wisconsin. They studied a group of women whळ్ were taking Enovid-E (mestranol $0.1 \mathrm{mg}$ an $\Phi^{\circ}$ norethynodrel $2.5 \mathrm{mg}$ ). After a $2 \mathrm{~g}$ oral dose of L-tryptophan the excretions of kynurenine? acetylkynurenine, 3-hydroxykynurenine, xan< thurenic acid and kynurenic acid were $a$ abnormally raised as compared with those in group of normal female controls (Price et al, 1967) 


\begin{tabular}{|c|c|c|c|c|c|}
\hline & \multicolumn{5}{|c|}{ Excretion (umole in $24 \mathrm{hr})^{2}$} \\
\hline & $K$ & $H K$ & $A c K$ & $X A$ & $K A$ \\
\hline Female controls (18) & $27 \cdot 5$ & $43 \cdot 1$ & $14 \cdot 5$ & $29 \cdot 8$ & $\begin{array}{r}59 \cdot 7 \\
+10 \cdot\end{array}$ \\
\hline Enovid-E group (10) & $\begin{array}{c} \pm 13.3 \\
171 \\
\pm 141\end{array}$ & $\begin{array}{l} \pm 140 \\
250 \\
+190\end{array}$ & $\begin{array}{l} \pm .5 \\
29.5 \\
+12.5\end{array}$ & $\begin{array}{l} \pm .02 \\
697 \\
+380\end{array}$ & $\begin{array}{r}101 \cdot 7 \\
+39 \cdot 1\end{array}$ \\
\hline $\begin{array}{l}\text { Enovid-E group (10) } \\
\text { after pyridoxine }\end{array}$ & $\begin{array}{r}22.1 \\
\pm 18.7\end{array}$ & $\begin{array}{r}25.7 \\
\pm 24.8\end{array}$ & $\begin{array}{r}13.1 \\
+\quad 3.9\end{array}$ & $\begin{array}{r}41.6 \\
\pm 10.0\end{array}$ & $\begin{array}{r}38.7 \\
+\quad 5.2\end{array}$ \\
\hline
\end{tabular}

Table 1 Tryptophan metabolite excretions after a $2 \mathrm{~g}$ L-tryptophan load ${ }^{1}$

'Price, Thornton, and Mueller (1967)

${ }^{2}$ The excretions of kynurenine (K), 3-hydroxykynurenine (HK,) acetylkynurenine (AcK), xanthurenic acid (XA), and kynurenic acid (KA) are given as the mean \pm SD.

The number in each group is indicated in brackets.

\begin{tabular}{lllrrrr}
\hline Sex & Age & Hormone and Dose & \multicolumn{3}{c}{ Excretion (mole in 8 hr) } \\
& $(y r)$ & & \multicolumn{1}{c}{$\boldsymbol{K}$} & \multicolumn{1}{c}{ HK } & \multicolumn{1}{c}{$X \boldsymbol{H}$} & $\mathrm{HA}$ \\
\hline M & 68 & Ethinyl oestradiol 0.25 mg daily & - & 1120 & 1099 & 1612 \\
M & 59 & Ethinyl oestradiol 0.25 mg alternate days & - & 423 & 662 & 136 \\
F & 72 & Ethinyl oestradiol 0.05 mg every 10 days & - & 909 & 1589 & 474 \\
F & 70 & Ethinyl oestradiol 0.25 mg every 3 days & - & 594 & 1186 & 305 \\
F & 24 & Ethinyl oestradiol 0.1 mg daily & 864 & 455 & 1320 & 436 \\
F & 57 & Stilboestrol 5 mg twice daily & 3226 & 1521 & 700 & 1105 \\
F & 55 & Stilboestrol 5 mg twice daily & 2582 & 1215 & 1230 & 689 \\
\hline
\end{tabular}

Table II The effect of oestrogens on tryptophan metaholism ${ }^{1}$

${ }^{1}$ Urine was collected for eight hours after a $5 \mathrm{~g}$ oral dose of L-tryptophan.

Treatment with pyridoxine hydrochloride, $25 \mathrm{mg}$ four times daily for two days, produced a dramatic reduction in the levels of all five metabolites, although the xanthurenic acid excretions were still above the control values (Table I).

The abnormal tryptophan metabolism associated with the use of oestrogen-progestogen preparations is due to the oestrogenic component. Table II shows the results obtained from a study of seven subjects who were receiving treatment with an oestrogen. In all cases the pattern was the same as that observed in women using the combined oestrogen-progestogen type of oral contraceptive. When ethinyl oestradiol, $0.1 \mathrm{mg}$, was given daily to a healthy young adult male volunteer the urinary excretions of xanthurenic acid and 3-hydroxykynurenine began to rise on the seventh day of treatment, and continued to do so throughout the five weeks during which the hormone was administered (Rose, 1966b).

Wolf has shown that treatment with a progestogen alone does not cause an elevation in the excretion of tryptophan metabolites (Brown, Rose, Price, and Wolf, 1969), and in fact results in a fall in the urinary levels of $N^{1}$-methylnicotinamide and 2-pyridone (Wolf, 1969).

All of the results discussed so far in this review were obtained from studies in which the urines were collected after the administration of an oral dose of L-tryptophan. Price et al (1967) have also analysed urine samples obtained without prior tryptophan loading, and they were unable to detect any difference between the excretion of metabolites by women using Enovid-E and by a control group. However, Toseland and S. A. Price (1969) have used thin-layer electrophoresis to determine the urinary excretion of 3-hydroxyanthranilic acid, and have found the output of this metabolite to be raised in the urine of women using oral contraceptives when the collections were made without giving a dose of the amino acid. J. M. Price and his colleagues did not include 3-hydroxyanthranilic acid in their study of tryptophan metabolite excretions.

Women taking Enovid-E excrete raised levels of $N^{1}$-methylnicotinamide, although their excretion of 2-pyridone remains unaltered (Rose et al, 1968). It is not necessary to administer a tryptophan load in order to demonstrate the increase in $N^{1}$-methylnicotinamide (Table III). Wolf (1969) has reported that the excretion of both nicotinic acid derivatives by male subjects is increased by treatment with stilboestrol, and so perhaps the failure of the 2-pyridone excretion to rise in the Enovid-treated women is due to a modifying influence of the progestational component.

The increased excretion of $N^{1}$-methylnicotinamide brought about by treatment with Enovid-E or stilboestrol indicates that oestrogens enhance the capacity for the conversion of tryptophan to nicotinic acid ribonucleotide. It is noteworthy that the excretions of tryptophan metabolites and the 2-pyridone (Brown

\begin{tabular}{|c|c|c|c|c|c|c|c|c|}
\hline & \multicolumn{6}{|c|}{ Excretion $(\mu$ moles $/ 24 \mathrm{hr})$} & \multicolumn{2}{|c|}{$\begin{array}{l}\text { Yield (after Tryptophan } \\
\text { less Spontaneous) }\end{array}$} \\
\hline & $\begin{array}{l}\text { Spontaneous } \\
N^{1} \mathrm{Me}\end{array}$ & & pyr & $\begin{array}{l}\text { After Tryptophan } \\
N^{1} \mathrm{Me}\end{array}$ & & $p y r$ & $N^{1} M e$ & pyr \\
\hline $\begin{array}{l}\text { Enovid-E group } \\
\text { ratio pyr/N'Me } \\
\text { Control group } \\
\text { ratio pyr } / \mathrm{N}^{1} \mathrm{Me}\end{array}$ & $\begin{array}{l}60 \cdot 0^{*} \pm 25 \cdot 7 \\
322 \pm 10 \cdot 5\end{array}$ & $\begin{array}{l}1.05 \\
2.65\end{array}$ & $\begin{array}{l}63 \cdot 5 \pm 26 \cdot 5 \\
85 \cdot 6 \pm 38 \cdot 4\end{array}$ & $\begin{array}{c}148 \cdot 3^{*} \pm 53 \cdot 3 \\
75 \cdot 4 \pm 65 \cdot 5\end{array}$ & $\begin{array}{l}0.91 \\
1.85\end{array}$ & $\begin{array}{l}136 \cdot 4 \pm 43 \cdot 4 \\
139 \cdot 9 \pm 72 \cdot 6\end{array}$ & $\begin{array}{r}88 \cdot 3 \pm 48 \cdot 4 \\
43 \cdot 9 \pm 58 \cdot 3\end{array}$ & $\begin{array}{l}72.9 \pm 29 \cdot 3 \\
54.2 \pm 53 \cdot 7\end{array}$ \\
\hline
\end{tabular}

Table III Effect of Enovid-E administration on the excretion of $N^{1}$-methylnicotinamide ( $\left.N^{1} M e\right)$ and 2-pyridone (pyr)

${ }^{1}$ The control group consists of 13 subjects with results for $\mathrm{N}^{1} \mathrm{Me}$ excretion and 24 subjects with pyr results. The results are expressed as mean $\pm \mathrm{SD}$. Those for the Enovid-E group marked * differ significantly from those of the control group; $\mathrm{P}<0.05$ (Student's $\mathrm{t}$ test). In all cases urine was collected for 24 hours. The L-tryptophan dose was $2 \mathrm{~g}$. 
Thornton, and Price, 1961) and $N^{1}$-methylnicotinamide (Hernandez, 1964) are also raised during the latter half of normal pregnancy. The most likely explanation is that these changes are due to the high circulating levels of oestrogens in pregnancy, although other factors, such as a temporary vitamin $\mathbf{B}_{6}$ depletion, may be an additional influence (Wachstein, Moore, and Graffeo, 1957; Wachstein, Kellner, and Otirz, 1960).

Mechanism of the Effect of Oestrogens on Tryptophan Metabolism

An acceleration in the conversion of tryptophan to nicotinic acid ribonucleotide might be achieved by an increase in the activity of one or more of the enzymes concerned with the metabolic sequence. The most likely candidate for such a role is tryptophan oxygenase because this enzyme catalyzes the first, irreversible and probably ratelimiting step on the pathway.

As discussed earlier, tryptophan oxygenase is inducible by adrenal glucocorticoids. Another such enzyme is alanine aminotransferase, the activity of which is raised in both liver and pancreas following the administration of cortisol. Keller, Richardson, and Yates (1969) have recently shown in the rat that when the level of plasma corticosteroids is raised by treatment with oestrogens there is an increase in the activity of hepatic, but not pancreatic, alanine aminotransferase. They suggest that this is because transcortin-bound corticosterone can gain access to the enzyme-producing systems in the liver cells by pinocytosis and there dissociate to yield free, physiologically functional steroid, but that the thick basement membrane of the pancreatic cells prevents such a passage of the protein-bound hormone. It is possible that oestrogens increase tryptophan oxygenase in liver cells by a similar mechanism.

A preliminary study of the effect of oestrogens on tryptophan oxygenase has been carried out by D. P. Rose and R. R. Brown at the Division of Clinical Oncology, University of Wisconsin. It was found that the level of activity of tryptophan oxygenase in rat liver is increased by the administration of a mestranol-norethynodrel combination, whereas oestradiol benzoate does not produce a consistent change (Fig. 3). A combination of oestradiol and progesterone apparently caused a reduction in enzyme activity, although further work is required to confirm this point. It is interesting that the synthetic and natural steroids should differ in their effect upon tryptophan oxygenase. A similar difference occurs in the case of liver kynureninase. In female rats, the activity of this enzyme is also raised by the mestranol-norethynodrel combination, whereas oestradiol is without effect. In male rats oestradiol

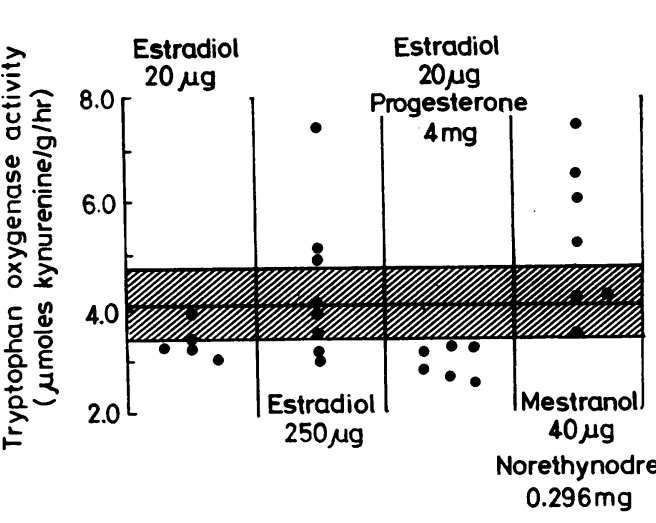

Fig. 3 The effect of oestradiol benzoate, $a$ combination of oestradiol and progesterone, and a combination of mestranol and norethynodrel on liver tryptophan oxygenase in female rats. The $250 \mu \mathrm{g}$ dose of oestradiol was given once daily for 14 days, and the other hormones once daily for 28 days. The stippled area indicates the range of activity for female controls (mean $\pm 2 S D)$.

has an inhibitory action (Rose and Brown, 1969)

If oestrogens cause an increased entry ob tryptophan into the tryptophan-nicotinic acis ribonucleotide pathway, then when a large dose्य of the amino acid is given to an oestrogen-treate subject, or to a woman receiving an oestrogen progestogen combination, there may be insuf $\overrightarrow{0}$ ficient pyridoxal 5-phosphate coenzyme available to allow further metabolism of all of the inter mediate metabolites that are produced. As a. consequence, there would then be an increase urinary excretion of the metabolites which are usually associated with vitamin $\mathbf{B}_{6}$ deficiency notably xanthurenic acid, 3-hydroxykynurenines and kynurenine. The occurrence of such 'relative deficiency' of pyridoxal 5-phosphatê would explain both why Price et al (1967) observed an abnormal excretion of metabolites only whe urine was collected after a tryptophan load, an $\bar{f}$. the occurrence of normal excretion levels when large doses of pyridoxine are given together with the amino acid.

An alternative explanation for the increaseg excretion of xanthurenic acid, kynurenine, and 3-hydroxykynurenine is that oestrogens, or theif conjugates, compete with pyridoxal phosphat for binding sites on apoenzyme molecules, in particular kynureninase and the aminotransferase responsible for the transamination of kynurening to yield kynurenic acid (Rose, 1966a). This suggestion stemmed from the observation bo Mason and Gullekson (1960) that sulphate esters of oestrogens inhibit rat kidney kynurening aminotransferase when added to the ass system in vitro, and that this inhibition varis 
inversely with the concentration of pyridoxal phosphate in the incubation mixtures. However, it has been found recently that liver kynurenine aminotransferase is unaffected by even massive doses of oestradiol benzoate $(250 \mu \mathrm{g}$ daily for 14 days), and, although oestradiol-treated male rats showed a significant reduction in kynureninase activity towards normal control female levels, this enzyme was not reduced in female rats receiving oestradiol. Female rats treated with a mestranolnorethynodrel combination actually show a significant increase in kynureninase levels, although the kynurenine aminotransferase activity is unaltered (Rose and Brown, 1969).

An explanation for the effect of oestrogens and oral contraceptives on tryptophan metabolism, which is based entirely on the possible inhibition of pyridoxal 5-phosphate-dependent enzymes, does not, of course, account for the increased excretion of $N^{1}$-methylnicotinamide.

\section{Possible Clinical Significance}

At the present time, the clinical significance of the abnormal metabolism of tryptophan by women using oral contraceptives is not known. There is no direct evidence of an occult vitamin $\mathbf{B}_{6}$ deficiency in such women, other than when they are subjected to an excessive intake of L-tryptophan, although the raised excretion of 3-hydroxyanthranilic acid and $N^{1}$-methylnicotinamide in urine collected without a prior dose of the amino acid indicates that metabolism of dietary tryptophan is increased along the pyridoxal phosphate-dependent pathway leading to nicotinic acid ribonucleotide synthesis. Nor has evidence been sought of a competitive inhibition of pyridoxal phosphate-requiring enzyme systems by conjugates of the oestrogenic component of oral contraceptives. It is important that the effect of administered oestrogens upon vitamin $\mathbf{B}_{6}$ metabolism be defined, for impairment of the function of this important coenzyme in women using oral contraceptives may contribute to disturbances of metabolism other than those concerned with tryptophan.

One complication of oral contraceptives which may be associated with abnormal tryptophan metabolism is depression. There is considerable evidence that the synthesis of 5-hydroxytryptamine from tryptophan is abnormally low in depressive illness, and that this may be related to the origin of the disorder.

Green and Curzon (1968) have found that the induction of tryptophan oxygenase in rat liver is followed by a decrease in brain 5-hydroxytryptamine. They suggest that in endogenous depression the high levels of plasma corticosteroids which are known to occur in the early morning produce an elevation in tryptophan oxygenase activity, and that this is responsible for the reduced 5-hydroxytryptamine synthesis because the available free tryptophan is diverted into the tryptophan-nicotinic acid ribonucleotide pathway. The presence of high tryptophan oxygenase activity in the livers of women taking oral contraceptives may result in low 5-hydroxytryptamine levels by a similar mechanism, and this may result in the appearance of a depressive state. An alternative possibility is that impaired 5-hydroxytryptamine synthesis may result from inhibition of 5-hydroxytryptophan decarboxylase (Fig. 1). This enzyme requires pyridoxal phosphate, and may therefore be susceptible to inhibition by competition between the coenzyme and oestrogen conjugates.

Much of my own work described in this review was carried out in the Department of Chemical Pathology, University of Sheffield, and I wish to thank Dr Arthur Jordan, head of that Department, for his interest and support.

\section{References}

Altman, K., and Greengard, O. (1966). Correlation of kynurenine excretion with liver tryptophan pyrrolase levels in disease and after hydrocortisone induction. J. clin. Invest., 45, 1527-1534.

Brown, R. R., Rose, D. P., Price, J. M., and Wolf, H. (1969). Tryptophan metabolism as affected by anovulatory agents. Ann. N.Y. Acad. Sci., 166, 44-56.

Brown, R. R., Thornton, M. J., and Price, J. M. (1961). The effect of vitamin supplementation on the urinary excretion of tryptophan metabolites by pregnant women. J. clin. Invest., 40, 617-623.

Green, A. R., and Curzon, G. (1968). Decrease of 5-hydroxytryptamine in the brain provoked by hydrocortisone and its prevention by allopurinol. Nature (Lond.), 220, 10951097.

Greengard, O. (1967). Specific enzyme responses in starved, glucagon-treated or irradiated rats, and general considerations on the mechanisms of induction in animals. In Advances in Enzyme Regulation, edited by G. Weber, vol. V, pp. 397-405. Pergamon Press, Oxford.

Greengard, O., Smith, M. A., and Acs, G. (1963). Relation of cortisone and synthesis of ribonucleic acid to induced and developmental enzyme function. J. biol. Chem., 238, 1548-1551.

Hernandez, T. (1964). Tryptophan metabolite excretion in pregnancy after a tryptophan load test. Fed. Froc., 23, 136.

Keller, N., Richardson, U. I., and Yates, F. E. (1969). Protein binding and the biological activity of corticosteroids: in vivo induction of hepatic and pancreatic alanine aminotransferases by corticosteroids in normal and estrogen-treated rats. Endocrinology, 84, 49-62.

Knox, W. E. (1951). Two mechanisms which increase in vivo the liver tryptophan peroxidase activity: specific enzyme adaptation and stimulation of the pituitary-adrenal system. Brit. J. exp. Path., 32, 462-469.

Mason, M., and Gullekson, E. H. (1960). Estrogen-enzyme interactions: inhibition and protection of kynurenine transaminase by the sulfate esters of diethylstilbestrol, estradiol, and estrone. J. biol. Chem., 235, 1312-1316.

Ogasawara, N., Hagino, Y., and Kotake, Y. (1962). Kynurenine transaminase, kynureninase, and the increase of xanthurenic acid excretion. J. Biochem. (Tokyo), 52, 162-166.

Price, J. M., Thornton, M. J., and Mueller, L. M. (1967). Tryptophan metabolism in women using steroid hormones for ovulation control. Amer. J. clin. Nutr., 20, 452-456.

Rose, D. P. (1966a). Excretion of xanthurenic acid in the urine of women taking progestogen-oestrogen preparations. Nature (Lond.), 210, 196-197.

Rose, D. P. (1966b). The influence of oestrogens on tryptophan metabolism in man. Clin. Sci., 31, 265-272. 
Rose, D. P., and Brown, R. R. (1969). The influence of sex and estrogens on liver kynureninase and kynurenine aminotransferase in the rat. Biochim. biophys. Acta (Amst.), 184, 412-419.

Rose, D. P., Brown, R. R., and Price, J. M. (1968). Metabolism of tryptophan to nicotinic acid derivatives by women taking oestrogen-progestogen preparations. Nature (Lond.), 219, 1259-1260.

Thomson, J. F., and Mikuta, E. T. (1954). The effect of cortisone and hydrocortisone on the tryptophan peroxidase-oxidase activity of rat liver. Endocrinology, 55, 232-233.

Toseland, P. A., and Price, S. A. (1969). Tryptophan and oral contraceptives. Brit. med. J., 1, 777.

Wachstein, M,. Kellner J. D., and Otirz, J. M. (1960). Pyridoxal phosphate in plasma and leukocytes of normal and pregnant subjects following $B_{6}$ load tests. Proc. Soc. exp. Bi (N.Y.), 103, 350-353.

Wachstein, M., Moore, C., and Graffec, L. W. (1957). Pyridox

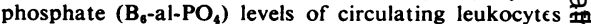
maternal and cord b'ood. Proc. Soc. exp. Biol. (N.Y.), 庹, 326-328.

Wolf, H. (1969). The effect of female sex hormones and hydr cortisone on NAD + biosynthesis from tryptophan in maxp Acta endocr. (Kbh.), Suppl. 138, 34.

Yess, N., Price, J. M., Brown, R. R., Swan, P. B., and Linkswile H. (1964). Vitamin $B_{6}$ depletion in man: urinary excreti\$్ of tryptophan metabolites. J. Nutr., 84, 229-236. 